\title{
Multiple pyogenic liver abscesses formed after appendectomy: The role of percutaneous drainage in a critically ill patient
}

\author{
Enver Zerem, Alma Sušić
}

Department of Gastroenterology University Clinical Center Tuzla

Tuzla, Bosnia and Herzegovina

Corresponding author:

Enver Zerem

The University Clinical Centar Tuzla

Trnovac bb

75000 Tuzla

Bosnia and Herzegovina

zerem@live.com

Tel.: + 38762344293

Fax.: + 38735266485

Received: 24 September 2012

Accepted: 15 October 2012

Copyright (C) 2012 by

Academy of Sciences and Arts

of Bosnia and Herzegovina.

E-mail for permission to publish:

amabih@anubih.ba

\begin{abstract}
Multiple pyogenic liver abscesses formed after appendectomy and their percutaneous treatment with multiple catheters have been rarely described. We report a case of multiple pyogenic liver abscesses in a critically ill patient, formed after appendectomy and treated successfully by antibiotics and drainage with six catheters that were introduced simultaneously under ultrasound control. Even though this was a case of liver abscess secondary to appendicitis, today very rare in Western countries, but still a serious complication in developing countries, it was successfully resolved by percutaneous drainage, along with antibiotic therapy. Conclusion. We emphasize the advantages of percutaneous treatment compared with surgery regarding the avoidance of perioperative complications and the risks of general anesthesia.
\end{abstract}

Key words: Interventional ultrasonography, Multiple simultaneous drainages, Antibiotic therapy.

\section{Introduction}

Pyogenic liver abscesses are usually caused by infection orginating in the biliary or intestinal tracts. This is a potentially lifethreatening disease so that appropriate diagnosis and treatment are very important. The overall mortality is high in patients with multiple liver abscesses (1-3). Abdominal ultrasonografy and computerized tomography are used most frequently in the diag- nosis of liver abscess. The diagnosis may be confirmed by image-guided percutaneous aspiration and drainage and then appropriate therapy can be planned according to culture and antibiogram $(4,5)$.

We report a case of multiple pyogenic liver abscesses formed after appendectomy and treated successfully by antibiotics and drainage with six catheters that were introduced simultaneously under ultrasound control. 


\section{Case report}

A 52-year-old man was admitted to our hospital with high fever, sweating and right upper abdominal pain that had lasted for seven days. On physical examination, he had marked tenderness in the right upper quadrant of the abdomen, his initial body temperature was $39.2{ }^{\circ} \mathrm{C}$, pulse and respiratory rates were 110 and 31 , respectively. His blood pressure was 90/70 $\mathrm{mmHg}$. Two months before admission he had undergone an emergency appendectomy for acute perforated appendicitis. He was in good health after that until 7 days before admission to our hospital. Laboratory tests were not performed during that period.

Laboratory tests performed on admission revealed erythrocyte sedimentation rate $94 \mathrm{~mm}$ /hour, C-reactive protein 205 $\mathrm{mg} / \mathrm{l}$ (normal $<3.3$ ), fibrinogen $9.4 \mathrm{~g} / \mathrm{l}$ (normal 1.8-3.5), WBC $18600 / \mathrm{mm}^{3}$, neutrophils $15240 / \mathrm{mm}^{3}$, hematocrit $29.5 \%$, platelets $273000 / \mathrm{mm} 3$, prothrombin time $33 \%$, aspartate aminotransferase $33 \mathrm{U} / \mathrm{l}$, alanine aminotransferase $44 \mathrm{U} / \mathrm{l}$, alkaline phosphatase $359 \mathrm{U} / \mathrm{l}$, gamma-glutamyl transpeptidase $541 \mathrm{U} / \mathrm{l}$, total bilirubin $71 \mu \mathrm{mol} / \mathrm{l}$, conjugated bilirubin $46 \mu \mathrm{mol} / \mathrm{l}$, total protein 61 $\mathrm{g} / \mathrm{l}$, albumin $21 \mathrm{~g} / \mathrm{l}$, globuline $40 \mathrm{~g} / \mathrm{l}, \mathrm{BUN}$ $8.8 \mathrm{mmol} / \mathrm{l}$, creatinine $100 \mu \mathrm{mol} / \mathrm{l}$, glucose $19.5 \mathrm{mmol} / \mathrm{l}$ and creatine kinase $206 \mathrm{U} / \mathrm{l}$.

Abdominal ultrasonography revealed that the hepatic parenchyma appeared diffusely heterogeneous and enlarged, with several heterogen-hypoechoic cystic lesions, that looked more like metastases, predominantly in the right lobe. Abdominal CT scan performed few days later confirmed the presence of multiple cystic formations with dense content varying in size, predominantly in the right lobe of the liver (Figure 1, Panel A and B).

Blood culture was performed when the patient had a high fever. The Serratia marcescens strain was found on two occasions.

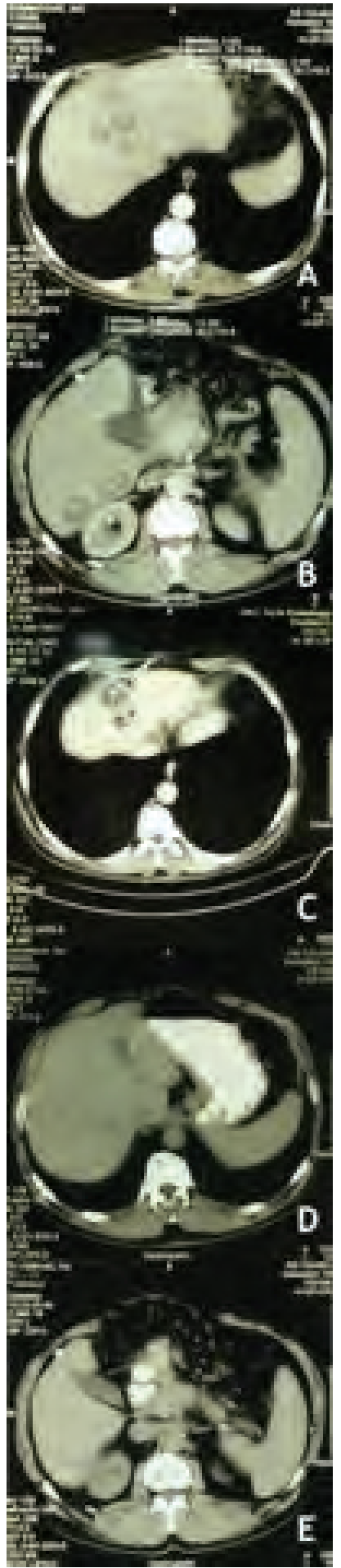

Figure 1 CT scans of multiple liver abscesses before treatment (Panels A and B), catheter inserted into abscess cavity (Panel C) and CT scans of the same parts of the liver three months after treatment (Panel $D$ and $E$ ). 
Cefazolin $1 \mathrm{~g}$ tid and gentamicin $1 \mathrm{mg} / \mathrm{kg}$ tid therapy was instituted before planned abscess drainage. Ultrasound guided percutaneous drainage was performed $48 \mathrm{~h}$ after hospital admission. We used $5 \mathrm{~F}$ pigtail polyethylene catheters (PBN Medicals, Denmark) which were inserted under US guidance. The six catheters were simultaneously introduced (Figure 2) into abscesses larger than $30 \mathrm{~mm}$ in the longest diameter and 80 $\mathrm{ml}$ of frank pus was obtained.

CT scan of one of abscess collection with catheter into cavity was performed, as shown in Figure 1 (Panel C). Escherichia coli and Serratia marcescens were found in cultures of the pus and they were sensitive to the formerly prescribed antibiotics. A total of $200 \mathrm{ml}$ of pus was drained through all six catheters during the following 10 days. The patient's clinical condition improved rapidly and fever subsided 3 days from the beginning of the treatment. Drainage catheters were subsequently removed between the 3rd and 10th days after introduction and the patient was discharged on the 15th day of hospitalization. Antibiotic therapy was changed from parenteral to oral on the 10th day and was stopped on the 28th day from the start of therapy. Ultrasound examination was done every day during catheter drainage, on discharge from the hospital, and 1, 3 and 6

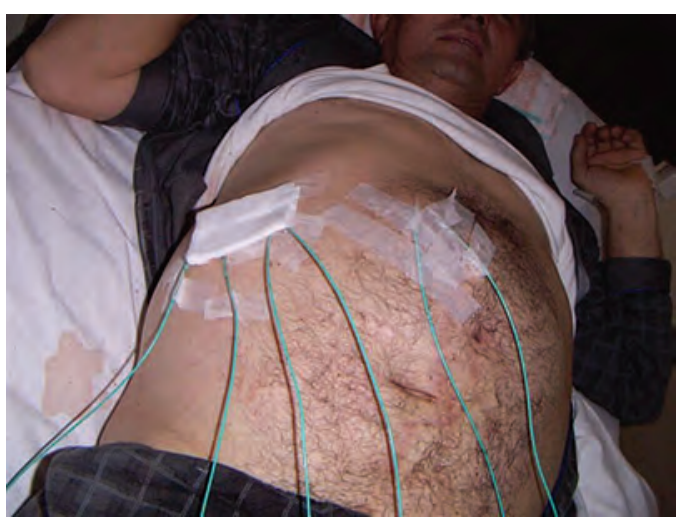

Figure 2 The patient with six catheters introduced simultaneously under ultrasound control. months after the discharge. The patient continued to do well during the follow-up period and a CT scan after 3 months (Figure 1 , Panel D and E) and ultrasonography after 6 months revealed that the abscess cavities had disappeared completely.

\section{Discussion}

Pyogenic liver abscess is a rare complication after appendectomy. Multiple pyogenic liver abscesses are not frequently reported in the literature, but the overall mortality is high, if left with no treatment or not treated early (2, 6). Pyogenic liver abscess usually develops secondary to biliary infections like cholecystitis, cholangitis, infection of deviscerated liver hydatid cyst (7) or infection of organs that are drained by the portal vein (diverticulitis, inflammatory bowel disease) (8). While studies of patients with infection of organs that are drained by portal vein suggest an increased incidence of portal bacteraemia, the development of liver abscesses in these patients is relatively rare (8). In the majority of cases, more than one organism is isolated from the abscesses (2). In our case two organisms were identified, suggesting that pyogenic liver abscesses could have been possibly caused by infection originating in the intestinal tract. However, we cannot rule out the formation of cryptogenic abscesses, since our patient underwent full recovery after the appendectomy and was free from any symptoms until 7 days before re-admission to our hospital.

In the past, antibiotic therapy and surgical drainage were considered the treatments of choice for liver abscess. Current therapeutic strategies established percutaneous drainage of liver abscesses instead of surgical treatment, with good results. The advantages of percutaneous treatment compared with surgery include external drainage without significant risks of intra-abdominal spillage and avoidance of perioperative complica- 
tions, the risks of general anaesthesia, less time and cost, better compliance and easier nursing care. This treatment is indicated especially when patients are in a critical condition postoperatively or when the risks of general anaesthesia or surgical drainage are substantial (9), unless the anatomic location is unsuitable and/or non-liquefied abscesses are present. Timely microbiological diagnosis, the combined use of new and old antibiotics and percutaneous treatment appear to be valuable in managing these serious conditions (10).

\section{Conclusion}

Liver abscess secondary to appendicitis, today very rare in Western countries, is still a possible and frightening complication in developing countries. In this case, simultaneous percutaneous drainage with 6 catheters, along with antibiotic therapy, were a safe and effective treatment for abscesses larger than $30 \mathrm{~mm}$ in the longest diameter, without complications related to the procedure. Abscess collections smaller than $30 \mathrm{~mm}$ in the longest diameter were successfully treated by antibiotics alone.

Authors' contributions: Conception, design and drafting the article: EZ; Acquisition, analysis and interpretation of data: AS.

Conflict of interest: The authors declare that they have no conflict of interest. This study was not sponsored by any external organization.

\section{References}

1. Lee KT, Wong SR, Sheen PC. Pyogenic liver abscess: an audit of 10 years' experience and analysis of risk factors. Dig Surg. 2001;18(6):459-66

2. Bahloul M, Chaari A, Bouaziz-Khlaf N, Kallel H, Herguefi L, Chelly H, et al. Multiple pyogenic liver abscess. World J Gastroenterol. 2006;12(18):29623.

3. Alvarez Perez JA, Gonzalez JJ, Baldonedo RF, Sanz L, Carreno G, Junco A, et al. Clinical course, treatment, and multivariate analysis of risk factors for pyogenic liver abscess. Am J Surg. 2001;181(2):177-86.

4. Seeto RK, Rockey DC. Pyogenic liver abscess. Changes in etiology, management, and outcome. Medicine (Baltimore). 1996;75(2):99-113.

5. Bergert H, Kersting S, Pyrc J, Saeger HD, Bunk A. Therapeutic options in the treatment of pyogenic liver abscess. Ultrashall Med. 2004;25(5):356-62.

6. Alvarez JA, Gonzalez JJ, Baldonedo RF, Sanz L, Carreno G, Jorge JI. Single and multiple pyogenic liver abscesses: etiology, clinical course, and outcome. Dig Surg. 2001;18(4):283-8.

7. Zerem E, Jusufović R. Percutaneous treatment of univesicular versus multivesicular hepatic hydatid cysts. Surg Endosc. 2006;20(10):1543-7.

8. Inoue T, Hirata I, Egashira Y, Ishida K, Kawakami $\mathrm{K}$, Morita E, et al. Refractory ulcerative colitis accompanied with cytomegalovirus colitis and multiple liver abscesses: A case report. World J Gastroenterol. 2005;11(33):5241-4

9. Zerem E, Bergsland J. Ultrasound guided percutaneous treatment of splenic abscesses: The significance in treatment of critically ill patients. World J Gastroenterol. 2006;12(45):7341-5.

10. Di Carlo P, Pantuso G, Cusimano A, D’Arpa F, Giammanco A, Gulotta G, et al. Two cases of monomicrobial intraabdominal abscesses due to KPC-3 Klebsiella pneumoniae ST258 clone. BMC Gastroenterol. 2011;11:103. 